\title{
Testosterone deficiency syndrome and cardiovascular health: Looking carefully at the evidence
}

\author{
Alvaro Morales, MD, CM, FRCS, FACS
}

Emeritus Professor of Urology, Queen's University, Kingston, ON

See related article on page 30 .

Cite as: Can Urol Assoc J 2014;8(1-2):34-5. hittp://dx.doi.org/10.5489/cuaj.1906 Published online February 10, 2014.

$\mathrm{T}$ he results of this regional study are interesting, but cannot be applied country-wide. ${ }^{1}$ Although the questionnaire used is not shown and there is no evidence that it was validated, the responders appear to be adequately informed and properly cautious on the management of a condition which is at the centre of considerable and, frequently poorly informed controversy. The controversy is bolstered by the "expert" views from all of walks of life: from endocrinologists and epidemiologists to urological surgeons and gerontologists, from the lay press to the regulatory agencies and from the pharmaceutical to the film industries. The result is cacophony of opinions creating much confusion and detriment to patients and physicians alike. ${ }^{2}$ Much of the brouhaha pertains to testosterone $(\mathrm{T})$ and prostate safety. ${ }^{3}$ The focus has now switched to the consequences of hypogonadism and T replacement therapy (TRT) in the context of cardiovascular health.

The paper cites some of the numerous publications supporting the use of TRT in men with TDS for its cardiovascular benefits. This should be weighed against 2 recent differing, high-profile studies (not cited) that need commentary. They are important not only because of their provenance, but also the quality and impact of the journals publishing them. Both, however, have flaws, but received considerable uncritical attention in the medical and lay media.

The first study ${ }^{4}$ showed increased cardiovascular adverse events (CVAEs) in elderly men (mean age: $74 \pm 5$ ) with serious mobility problems on TRT. In addition to the subjects' physical limitations and the fact that the study was not designed to assess CVAEs, many of the participants reached supraphysiological T values during $\mathrm{T}$ therapy, a bad idea, accord- ing to the Endocrine Society Guideline. ${ }^{5}$ There was a distinct increased proportion of CVAEs in those reaching $T$ levels $>1000 \mathrm{ng} / \mathrm{dL}(34.6 \mathrm{nmol} / \mathrm{L})$, and a lesser increase in those with levels between 500 to $1000 \mathrm{ng} / \mathrm{dL}$ (17.3-34.6 nmol/L) and even fewer among subjects with levels $£ 500 \mathrm{ng} / \mathrm{dL}$. Furthermore, in the T group, "as compared with the placebo group there was a significant increase in hemoglobin and hematocrit." The large TIMERISK study in younger and healthier men convincingly showed that borderline polycythemia is associated with increased risk of cardiovascular mortality. ${ }^{6}$ It is little wonder that the study had to be stopped.

The second study ${ }^{7}$ is more problematic. The accompanying editorial ${ }^{8}$ pointed to some of its weaknesses, including: (1) its retrospective nature with linkage of results of a single T determination with pharmacy data, (2) the "frustrating little information... whether TRT was appropriately prescribed" and (3) "the generalizability of the results to the broader population." Dr. Richard Bebb (Vancouver, BC) provided further insights: a. the subjects were already at high risk of heart attack and stroke as $80 \%$ had documented coronary artery disease, b. as a retrospective study it is "hypothesis generating" but presents no factual evidence, c. why and how did the physicians decided to measure $\mathrm{T}$ but to treat some men but not others? $d$. of those prescribed T, $17.6 \%$ did not renew their initial prescription (personal communication, 2013). To the above I would add that the extensive and sophisticated statistical methodology employed does not eliminate the inherit bias of the study or the follow-up, which is too short for current standards. Details of the total $\mathrm{T}$ measurement are absent and no reason is given as to why they received TRT. The mean duration of treatment was just over 1 year and $82.4 \%$ filled more than 1 prescription, but there is no information as to how many thereafter. Most bothersome is the absence of hematology data.

Despite their flaws, the 2 papers shouldn't be dismissed, but evaluated thoughtfully together with the ones showing positive results with TRT. These data will assist urologists in 
their role in educating colleagues regarding testosterone deficiency syndrome, cardiovascular mortality and risk factors. ${ }^{8}$

Competing interests: Dr. Morales declares no competing financial or personal interests.

\section{References}

1. Wallis CJD, Nelson HL, Pommerville PJ. Testosterone deficiency syndrome and cardiovascular health: An assessment of beliefs, knowledge and practice patterns of general practitioners and cardiologists in Victoria, BC. Can Urol Assoc J 2014;8:30-3. http://dx.doi.org/10.5489/cuaj.1448

2. Morales A. The long and tortuous history of the discovery of testosterone and its clinical application. J Sex Med 2013;10:1178-83. http://dx.doi.org/10.1111/ism.12081

3. Khera M, Crawford D, Morales A, et al. A new era of testosterone and prostate cancer: From physiology to clinical complications. Eur Urol 2014;65:115-23. http://dx.doi.org/10.1016/i.eururo.2013.08.015
4. Basaria S, Coviello AD, Travison TG, et al. Adverse events associated with testosterone administration. $N$ Engl J Med 2010;362:109-22. http://dx.doi.org/10.1056/NEJMoa1000485

5. Bhasin $\mathrm{S}$, Cunningham GR, Hayes FJ, et al. Testosterone therapy in adult men with androgen deficiency syndromes: An Endocrine Society Clinical Practice Guideline. J Clin Endocrinol Metab 2010;95:2536-59. http://dx.doi.org/10.1210/ic.2009-2354

6. Kunnas T, Solakivi T, Huuskonen $\mathrm{K}$, et al. Hematocrit and the risk of coronary heart disease and mortality in the TIMERIK study, a 28 year follow-up. Prev Med 2009;49:45-7. http://dx.doi.org/10.1016/i. ypmed.2009.04.015

7. Vigen $\mathrm{R}, \mathrm{O}^{\prime}$ Donell $\mathrm{Cl}$, Barón AE, et al. Association of testosterone therapy with mortality, myocardial infarction, and stroke in men with low testosterone levels. JAMA 2013;310:1829-36. http://dx.doi. org/10.1001/jama.2013.280386

8. Cappola AR. Testosterone therapy and risk of cardiovascular disease. JAMA 2013;310:1805-6. http:// dx.doi.org/10.1001/jama.2013.280387

Correspondence: Dr. Alvaro Morales, Emeritus Professor of Urology, Queen's University, Kingston, ON; moralesa@queensu.ca 